\title{
Effect of multi-walled carbon nanotube addition on the microstructures and mechanical properties of $\mathrm{Ti}(\mathrm{C}, \mathrm{N})$-based cermets
}

\author{
P. WU*, S. C. LIU, X. R. JIANG \\ College of Chemistry and Materials Science, Longyan University, Longyan 364000, China \\ Received: December 19, 2017; Accepted: December 25, 2017 \\ (C) The Author(s) 2017. This article is published with open access at Springerlink.com
}

\begin{abstract}
The surface modification of multi-walled carbon nanotubes (MWCNTs) was carried out using plasma treatment. The microstructures of the prepared cermets with different additions of MWCNTs were investigated by scanning electron microscopy (SEM), transmission electron microscopy (TEM), energy dispersive X-ray analysis (EDX), and X-ray diffraction (XRD). Mechanical properties such as transverse rupture strength (TRS), fracture toughness $\left(K_{\mathrm{IC}}\right)$, and hardness (HRA) were measured. The results showed that some reactive groups were successfully modified on the surface of MWCNTs, resulting in the improvement of dispersibility. Most of the amorphous carbons and impurities were peeled from the MWCNTs. Increasing MWCNT addition decreased the dissolution of tungsten, titanium, and molybdenum in the binder phase. The cermet with $0.5 \mathrm{wt} \%$ MWCNT addition showed the highest TRS and fracture toughness. The strengthening mechanisms were attributed to the finer grain size, the homogeneous microstructure, and the higher volume fraction of binder phase in the binder. The toughening mechanisms were characterized by bridging and pulling-out.
\end{abstract}

Keywords: Ti(C,N)-based cermets; microstructure; mechanical property; fracture toughness

\section{Introduction}

Ti(C,N)-based cermets have attracted much attention because of excellent wear-resistance, high hardness at high temperature, perfect chemical stability, very low friction coefficient to metals, and superior thermal deformation resistance [1]. However, the inherent brittleness has long prevented the cermets from being used with wide application.

In recent years, the discovery of carbon nanotubes has generated considerable interest in their use as

\footnotetext{
* Corresponding author.

E-mail: 365103755@qq.com
}

reinforcements or functionalizing elements in different materials, including polymers [2,3], metals [4,5], and ceramics [6-8]. Compared with all kinds of natural materials, carbon nanotubes have immense aspect ratio, low density, exceptional high axial strength, high electrical conductivity, good thermal conductivity, fiber-like structure, and exceptional resilience $[9,10]$. However, the homogeneous dispersion of multi-walled carbon nanotubes (MWCNTs) in the composites is difficult. The inactive surface (containing a layer of amorphous carbon) of MWCNTs makes weak interfacial bonding between matrix and MWCNTs [11]. To overcome these problems, the modification of the MWCNTs has proven to be efficient.

At present, the commonly used methods for modifying 
the MWCNTs are electrochemical treatment [12], polymer wrapping [13], and mechanic-chemical treatment [14]. Compared with other modification methods, the plasma treatment method has been widely used for surface activation of various materials, such as organic polymer [15], metals [16], and ceramics [17], which was due to its nonpolluting character and shorter reaction time. However, the MWCNTs modified by the plasma treatment method have not been reported up to date. $\operatorname{Ti}(\mathrm{C}, \mathrm{N})$-based cermets reinforced and toughened by carbon nanotube addition have been less focused. Ti(C,N)-based cermets were mostly used as cutting tools. MWCNTs would not have any loss under the temperature below $1200{ }^{\circ} \mathrm{C}$ [18], while the working temperature during industrial applications of the cermets was under $1000{ }^{\circ} \mathrm{C}$.

In the present study, the plasma treatment method was used to modify the MWCNTs. The effects of MWCNT addition on the microstructures and mechanical properties of $\mathrm{Ti}(\mathrm{C}, \mathrm{N})$-based cermets were investigated. The strengthening and toughening mechanisms were also studied.

\section{Experimental procedure}

Commercially available $\operatorname{TiC}(0.51 \mu \mathrm{m}), \operatorname{TiN}(0.52 \mu \mathrm{m})$, WC $(0.85 \mu \mathrm{m})$, Mo $(2.60 \mu \mathrm{m})$, Ni $(1.70 \mu \mathrm{m})$, Co $(2.46 \mu \mathrm{m}), \mathrm{Cr}_{3} \mathrm{C}_{2}(3.2 \mu \mathrm{m}), \mathrm{C}(5.5 \mu \mathrm{m})$, and MWCNTs were used as raw materials. The MWCNTs used in the present study have an average diameter of $60-100 \mathrm{~nm}$ and a length of $5-15 \mu \mathrm{m}$ supplied by Shenzhen Nanotech. Port. Co. Ltd., China. The MWCNTs were plasma treated by plasma equipment. The plasma treated conditions for MWCNTs were as follows: operating voltage of $550 \mathrm{~V}$, input power of $55 \mathrm{~W}$, operating pressure of $50 \mathrm{~Pa}$, and process duration of $30 \mathrm{~min}$. The compositions of the cermets with different MWCNT additions considered in the present study are given in Table 1.

Table 1 Composition design of the experimental materials (Unit: $\mathrm{wt} \%$ )

\begin{tabular}{ccccccccc}
\hline Cermet & $\mathrm{TiC}$ & $\mathrm{TiN}$ & $\mathrm{Ni}+\mathrm{Co}$ & $\mathrm{Mo}$ & $\mathrm{WC}$ & $\mathrm{Cr}_{3} \mathrm{C}_{2}$ & $\mathrm{C}$ & MWCNTs \\
\hline $\mathrm{A}$ & 34.8 & 10.6 & 23 & 16 & 13.7 & 0.6 & 1.1 & 0.2 \\
$\mathrm{~B}$ & 34.5 & 10.6 & 23 & 16 & 13.7 & 0.6 & 1.1 & 0.5 \\
$\mathrm{C}$ & 34.2 & 10.6 & 23 & 16 & 13.7 & 0.6 & 1.1 & 0.8 \\
$\mathrm{D}$ & 33.0 & 10.6 & 23 & 16 & 13.7 & 0.6 & 1.1 & 2.0 \\
\hline
\end{tabular}

These powders were dispersed homogeneously and mixed in a QM-1SP planetary ball mill for $22 \mathrm{~h}$ with a mass ratio of cemented carbide balls to mixture being $7: 1$ and the rotational speed being $260 \mathrm{rpm}$. The modified MWCNTs, which were dispersed in alcohol for $30 \mathrm{~min}$ by ultrasonication, were mixed with the powders for $2 \mathrm{~h}$. After mixing, the slurries were dried at $353 \mathrm{~K}$ in an infrared stove, and then sieved through 80 mesh. The powders were pressed into green compacts with dimensions of $39 \mathrm{~mm} \times 8 \mathrm{~mm} \times 8 \mathrm{~mm}$. Finally, the green compacts were sintered at $1683 \mathrm{~K}$ in vacuum for $1 \mathrm{~h}$. The vacuum was controlled at $10^{-2}-1 \mathrm{~Pa}$ during liquid sintering.

The FTIR spectra of pristine and plasma treated MWCNTs were characterized by a Bruker Vector 22 spectrophotometer. The transverse rupture strength (TRS) and Rockwell hardness (HRA) were measured. The CMM-50 optical microscope was used to test the porosity according to the international standards (ISO/BIS4505). "A" represents the pores whose diameters are smaller than or equal to $10 \mu \mathrm{m}$. The pores whose diameters are larger than $10 \mu \mathrm{m}$ but smaller than $25 \mu \mathrm{m}$ are called " $\mathrm{B}$ " pores. " $\mathrm{C}$ " represents the free carbon [19]. The fracture toughness $\left(K_{\mathrm{IC}}\right)$ of the sintered cermets was determined by measuring the crack length near the indent made by Vickers indentation load of $30 \mathrm{~kg}$ and calculated by using the following equation [20]:

$$
K_{\mathrm{IC}}=0.15 \sqrt{\frac{30 H V}{\sum_{i=1}^{4} l_{i}}}
$$

where $l_{i}$ is the length of the crack tip from the hardness indent in $\mathrm{mm}$.

The microstructures were observed by a QVANTA2000 scanning electron microscope (SEM) in backscattered electron (BSE) mode. The fracture surface morphology was observed by LEO1550 SEM in secondary electron (SE) mode, and the distribution of the elements was determined by energy dispersive X-ray analysis (EDX; Genesis 2000) in combination with SEM. The mean grain size and binder volume fraction of the BSE images were measured by IPP6.0 image analysis software. The morphology of pristine and plasma treated MWCNTs was characterized by a JEM-2000EX transmission electron microscope (TEM). The X-ray diffraction analysis (XRD) of the specimens was performed by using $\mathrm{Cu} \mathrm{Ka}$ radiation (D8ADVANCEX X-ray diffractometer). The lattice parameters of main phases were measured by a standard procedure. 


\section{Results and discussion}

\section{1 Modification of MWCNTs}

The TEM micrographs of MWCNTs are shown in Fig. 1. The pristine MWCNTs are usually curved and twisted with each other, and have some amorphous carbons (black spots), as shown in Fig. 1(a). Some impurity in bundle is shown in Fig. 1(c). After plasma treatment, the amorphous carbons and impurity decrease evidently, and the dispersibility of MWCNTs increases simultaneously, as shown in Figs. 1(b) and 1(d). In the process of plasma treatment, the carbon nuclei of MWCNTs receive the energy from the ion bombardment, which results in the creation of vacancies and interstitials in MWCNTs. Then, the amorphous carbons are loosened due to ion sweeping. Finally, most of the amorphous carbons and impurities are peeled from the MWCNTs [21].

The FTIR spectra of MWCNTs are shown in Fig. 2. Compared with the FTIR spectrum of pristine MWCNTs, the FTIR spectrum of P-MWCNTs clearly shows that the appearance of the peaks at 1580 and
$1645 \mathrm{~cm}^{-1}$ is associated with amide group and carbonyl group, respectively. The peak at $1118 \mathrm{~cm}^{-1}$ is due to $\mathrm{C}-\mathrm{N}$ stretching. And the intensity of the peak at $3420 \mathrm{~cm}^{-1}$ related to $\mathrm{N}-\mathrm{H}$ stretching shows an increasing trend. These results indicate that some reactive groups are successfully modified on the surface of MWCNTs, which is beneficial to sensitization and activation treatment of MWCNTs, resulting in the improvement of dispersibility of MWCNTs.

\section{2 Microstructure}

The microstructures of the cermets are shown in Fig. 3. The four cermets show a typical microstructure consisting of hard core, rim phase, and binder phase. It is found that the grain size of the cermets is influenced by the addition of MWCNTs. The effects of the addition amount of MWCNTs on the mean grain size of the cermets are shown in Table 2. The grain size of the cermets decreases slightly with increasing MWCNT addition from 0.2 to $0.5 \mathrm{wt} \%$. However, when the MWCNT addition increases further above $0.5 \mathrm{wt} \%$, the grain size of the cermets increases.
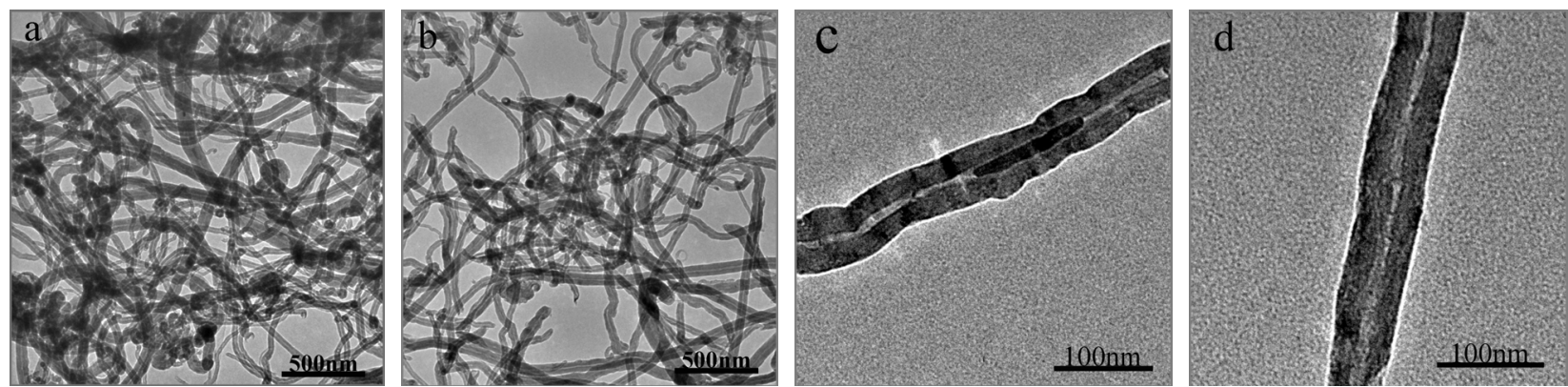

Fig. 1 TEM micrographs of (a) pristine MWCNTs, (b) plasma treated MWCNTs (P-MWCNTs), (c) high magnification of pristine MWCNTs, and (d) high magnification of P-MWCNTs.

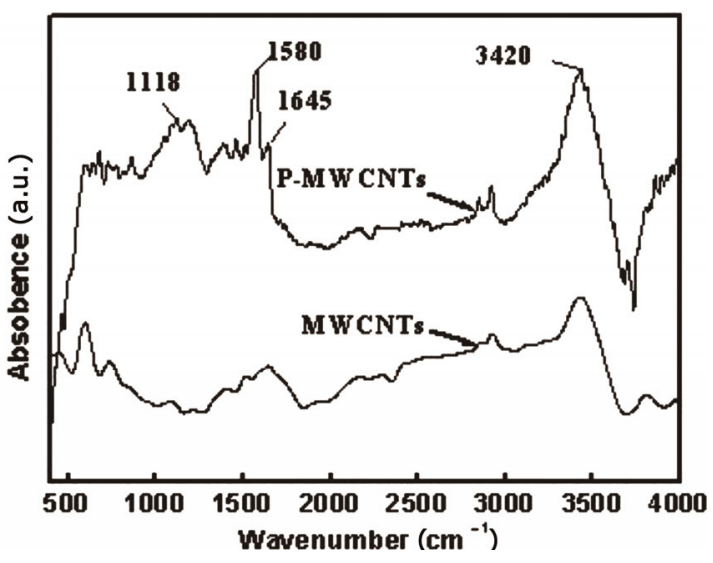

Fig. 2 FTIR spectra of the pristine and plasma-treated MWCNTs.
The content of main alloy elements in the binder phase was determined by EDX, and the results are summarized in Table 3. The dissolution of Ti, $\mathrm{W}$, and Mo in the binder phase decreases with increasing MWCNT addition.

The distribution of MWCNTs along the grain boundaries decreases the solubility of hard phase in the binder phase, which inhibits the growth of grains [22]. The results suggest that appropriate amount of MWCNTs has a positive effect on grain refinement. The increase of grain size for cermets with 0.8 and $2.0 \mathrm{wt} \%$ MWCNT additions is due to the poor wetting between the hard phase and binder phase. The solubility of these carbides in Ni phase decreases with increasing 

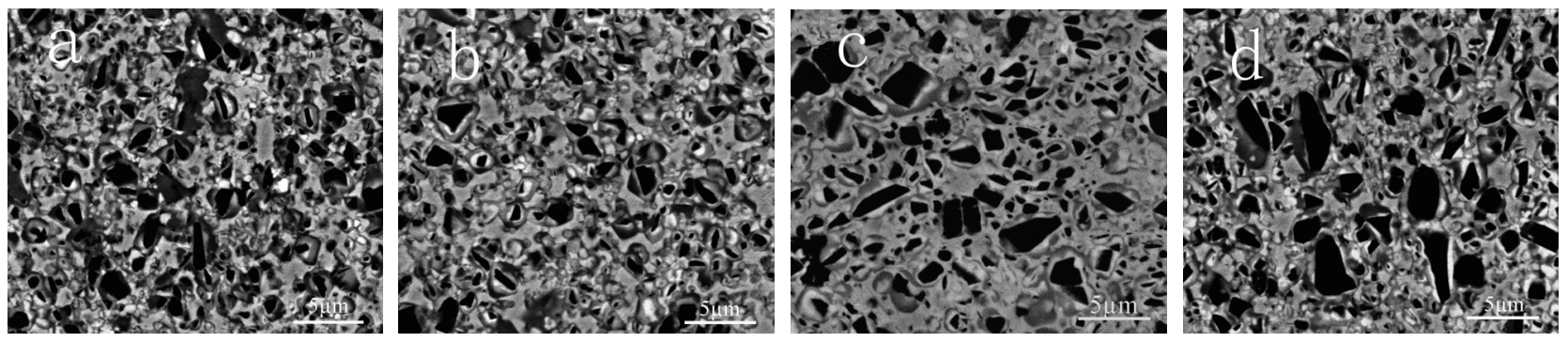

Fig. 3 Microstructures of Ti(C,N)-based cermets with the MWCNT addition of: (a) $0.2 \mathrm{wt} \%$, (b) $0.5 \mathrm{wt} \%$, (c) $0.8 \mathrm{wt} \%$, and (d) $2.0 \mathrm{wt} \%$.

MWCNT addition, resulting in the decrease of the solid-liquid interfacial energy $\gamma_{\mathrm{SL}}$. Thereby the wetting angle increases with increasing MWCNT addition and accordingly reduces the wettability of the ceramic grains by liquid metal during sintering, resulting in the aggregation of ceramic grains.

The lattice parameters of $\mathrm{Ni}$ phase in the cermets with MWCNT addition were determined from XRD data, and are summarized in Table 4. It shows that the lattice parameters of $\mathrm{Ni}$ are influenced by the addition of MWCNTs. The lattice parameters of Ni decrease with increasing MWCNT addition, which indicates that the dissolution of Mo, $\mathrm{W}$, and $\mathrm{Ti}$ in Ni decreases with increasing MWCNT addition. Although carbon nanotubes have high thermo stability, some of them would resolve in the form of $\mathrm{C}$ atoms during sintering process. It was reported that the lattice parameters of

Table 2 Effect of the MWCNT addition on the mean grain size of the cermets

\begin{tabular}{lcccc}
\hline Addition of MWCNTs $(\mathrm{wt} \%)$ & 0.2 & 0.5 & 0.8 & 2.0 \\
Mean grain size $(\mu \mathrm{m})$ & 1.59 & 1.48 & 1.71 & 1.80 \\
\hline
\end{tabular}

Table 3 Effect of the MWCNT addition on the element content of the binder

\begin{tabular}{cccc}
\hline MWCNT addition (wt\%) & W & Mo & Ti \\
\hline 0.2 & 9.18 & 10.05 & 9.07 \\
0.5 & 8.55 & 7.33 & 7.54 \\
0.8 & 6.90 & 7.08 & 7.06 \\
2.0 & 6.33 & 7.18 & 4.30 \\
\hline
\end{tabular}

Table 4 Lattice parameters of $\mathrm{Ni}$ phase and binder volume fraction of the cermets

\begin{tabular}{ccc}
\hline $\begin{array}{c}\text { MWCNT } \\
\text { addition }(\mathrm{wt} \%)\end{array}$ & $\begin{array}{c}\text { Lattice parameter } \\
\text { of Ni phase }(\mathrm{nm})\end{array}$ & $\begin{array}{c}\text { Binder volume } \\
\text { fraction (vol\%) }\end{array}$ \\
\hline 0.2 & 0.3580 & 48.66 \\
0.5 & 0.3568 & 53.25 \\
0.8 & 0.3561 & 49.63 \\
2.0 & 0.3550 & 45.53 \\
\hline
\end{tabular}

Ni phase decrease with increasing carbon addition [23]. Clearly, the XRD results correspond well with EDX results in the present study.

The binder volume fractions of the cermets are also shown in Table 4. The binder volume fraction of the cermets increases firstly and then turns to decrease with increasing MWCNT addition. The cermet with $0.5 \mathrm{wt} \%$ MWCNT addition have the highest binder volume fraction.

The porosities of the four cermets are shown in Table 5 . The porosities decrease firstly and then turn to increase. The porosity for cermet with $0.5 \mathrm{wt} \% \mathrm{MWCNT}$ addition is the lowest. When the MWCNT addition is from 0.2 to $0.5 \mathrm{wt} \%$, the MWCNTs disperse homogeneously in the cermets. The porosity of the cermets decreases slightly. However, when the MWCNT addition is higher than $0.5 \mathrm{wt} \%$, the MWCNTs are increasingly difficult to be dispersed homogeneously in the cermets, and the wettability becomes bad between the hard phase and binder phase, which results from the decreased dissolution of Mo in the binder phase with increasing MWCNT addition. During sintering, $\mathrm{Mo}_{2} \mathrm{C}$ is formed firstly, and then the surface of the hard phase is surrounded by the rim phase (Ti, W, Mo) (C, $\mathrm{N})$, which improves the wettability between hard phase and binder phase. The solubility of Mo decreases with increasing MWCNT addition, so the wettability decreases with increasing MWCNT addition. Thus, the densification of the cermets is inhibited, which results in an increase of porosity.

\section{3 Mechanical properties}

TRS, hardness, and fracture toughness were measured at room temperature, and the results are summarized in Table 6.

Table 5 Porosities of the cermets

\begin{tabular}{cllll}
\hline Cermet & \multicolumn{1}{c}{ A } & \multicolumn{1}{c}{ B } & \multicolumn{1}{c}{ C } & \multicolumn{1}{c}{ D } \\
\hline \multirow{2}{*}{ Porosity } & A06 B02 & A04 B02 & A08 B06 & A08 B08 \\
& C00 & C00 & C00 & C00 \\
\hline
\end{tabular}


Table 6 Mechanical properties of cermets

\begin{tabular}{cccc}
\hline Cermet & TRS (MPa) & Hardness (HRA) & $\begin{array}{c}\text { Fracture toughness, } \\
K_{\mathrm{IC}}\left(\mathrm{MPa} \cdot \mathrm{m}^{1 / 2}\right)\end{array}$ \\
\hline $\mathrm{A}$ & $1902_{-108}^{+121}$ & $90.4_{-0.1}^{+0.3}$ & $13.3_{-0.5}^{+0.3}$ \\
$\mathrm{~B}$ & $2181_{-109}^{+84}$ & $91.0_{-0.2}^{+0.4}$ & $14.9_{-0.3}^{+0.7}$ \\
$\mathrm{C}$ & $1852_{-135}^{+79}$ & $90.8_{-0.4}^{+0.2}$ & $13.0_{-0.3}^{+0.4}$ \\
$\mathrm{D}$ & $1300_{-147}^{+164}$ & $89.0_{-0.6}^{+0.5}$ & $11.9_{-0.8}^{+0.6}$ \\
\hline
\end{tabular}

The cermet with $0.5 \mathrm{wt} \%$ MWCNT addition shows the highest TRS. The finer grain size, the homogeneous microstructure, and the higher volume fraction of binder phase are the explanations of this behavior. The hardness of the cermets changes slightly with increasing MWCNT addition. When the MWCNT addition increases further to $2.0 \mathrm{wt} \%$, the TRS and hardness of the cermets decrease dramatically, which result from the increasing porosity and agglomeration of MWCNTs in the cermets.

The fracture surfaces of the four cermets were examined by SEM, as shown in Fig. 4, all of which consist of ceramic grains, concavities formed by the removal of ceramic grains, tearing ridges formed by the tearing of the metal phase, and dimples along the expanding paths of the tearing ridges. Compared with the fracture surfaces of the other cermets, more tearing ridges, less intergranular fracture, more dimples, and greater plastic deformation are observed for cermet with $0.5 \mathrm{wt} \%$ MWCNT addition, which result in a strong interfacial bond and an improvement of TRS.

The cermet with $0.5 \mathrm{wt} \%$ MWCNT addition exhibits the highest fracture toughness of $14.9 \mathrm{MPa} \cdot \mathrm{m}^{1 / 2}$. To explain this phenomenon, the fracture surface observation was carried out for the cermets. The high magnification fracture surfaces for cermet with $0.5 \mathrm{wt} \%$ MWCNT addition are shown in Fig. 5. Obviously, the pulling-out (white arrow) for cermet with $0.5 \mathrm{wt} \%$ MWCNT addition appears in Fig. 5(a). The pullout length of
MWCNTs is very short, which is due to strong bonding strength and shearing strength in the interface, which absorb crack propagating energy during fracture, resulting in the improved toughness. Some MWCNTs are bonding to the cermets in "bridging" manner (white arrow), as shown in Fig. 5(b). The MWCNTs are embedded into and pin the grains of the cermets, which indicate the strong interface between the MWCNTs and the grains. However, the direct mechanical contact with cemented carbide balls during ball milling results in damage and breakage of MWCNTs (black arrow), which is considered to be detrimental to the substantial increase of the fracture toughness.

\section{Conclusions}

(1) The surface modification of multi-walled carbon nanotubes (MWCNTs) was carried out using the plasma treatment method. Most of the amorphous carbons and impurities were peeled from the MWCNTs. Some reactive groups were successfully modified on the surface of MWCNTs, resulting in the improvement of dispersibility.

(2) An increasing MWCNT addition decreased the dissolution of tungsten, titanium, and molybdenum in the binder phase. The cermet with $0.5 \mathrm{wt} \% \mathrm{MWCNT}$ addition exhibited the smallest grain size. The porosity of the cermets increased with increasing MWCNT addition.

(3) The cermet with $0.5 \mathrm{wt} \%$ MWCNT addition showed the highest TRS and fracture toughness. The strengthening mechanisms were attributed to the finer grain size, the homogeneous microstructure, and the higher volume fraction of binder phase. The toughening mechanisms were characterized by bridging and pulling-out.
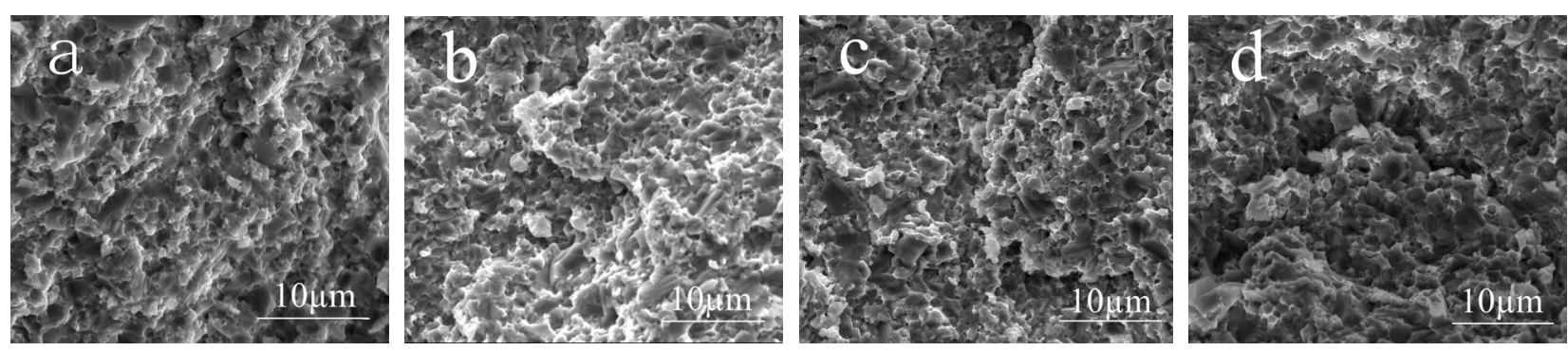

Fig. 4 Fracture surface of Ti(C,N)-based cermets with the MWCNT addition of: (a) $0.2 \mathrm{wt} \%$, (b) $0.5 \mathrm{wt} \%$, (c) $0.8 \mathrm{wt} \%$, and (d) 2.0 wt.\%. 


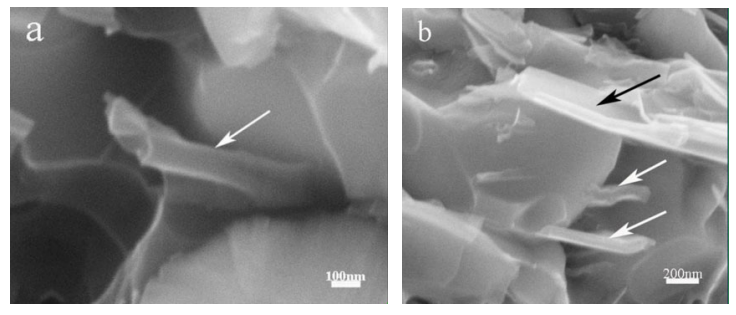

Fig. 5 Fracture surfaces for cermet with $0.5 \mathrm{wt} \%$ MWCNT addition: (a) low magnification, (b) high magnification.

\section{Acknowledgements}

This research was financially supported by the Science and Technology Department of Fujian Province under Project No. 2014H0037, the Production, Education and Research of Fujian Provincial Education Department under Project No. JK2016040, and the Key Subject Project of Fujian Province.

\section{References}

[1] Moskowitz D, Terner LL. TiN improves properties of titanium carbonitride-base materials. Int $J$ Refract Met $H$ 1986, 5: 13.

[2] Ajayan PM, Schadler LS, Giannaris C, et al. Single-walled carbon nanotube-polymer composites: Strength and weakness. Adv Mater 2000, 12: 750-753.

[3] Xie X-L, Mai Y-W, Zhou X-P. Dispersion and alignment of carbon nanotubes in polymer matrix: A review. Mat Sci Eng R 2005, 49: 89-112.

[4] Zhou S, Zhang X, Ding Z, et al. Fabrication and tribological properties of carbon nanotubes reinforced $\mathrm{Al}$ composites prepared by pressureless infiltration technique. Composites Part A 2007, 38: 301-306.

[5] Feng Y, Yuan HL, Zhang M. Fabrication and properties of silver-matrix composites reinforced by carbon nanotubes. Mater Charact 2005, 55: 211-218.

[6] Zhan G-D, Kuntz JD, Wan J, et al. Single-wall carbon nanotubes as attractive toughening agents in alumina-based nanocomposites. Nat Mater 2003, 2: 38-42.

[7] Wang X, Padture NP, Tanaka H. Contact-damage-resistant ceramic/single-wall carbon nanotubes and ceramic/graphite composites. Nat Mater 2004, 3: 539-544.

[8] Duszová A, Dusza J, Tomášek K, et al. Microstructure and properties of carbon nanotube/zirconia composite. J Eur Ceram Soc 2008, 28: 1023-1027.

[9] Ruoff RS, Lorents DC. Mechanical and thermal properties of carbon nanotubes. Carbon 1995, 33: 925-930.
[10] Iijima S. Helical microtubules of graphitic carbon. Nature 1991, 354: 56-58.

[11] Dalmas F, Chazeau L, Gauthier C, et al. Multiwalled carbon nanotube/polymer nanocomposites: Processing and properties. J Polym Sci Pol Phys 2005, 43: 1186-1197.

[12] Bahr JL, Yang J, Kosynkin DV, et al. Functionalization of carbon nanotubes by electrochemical reduction of aryl diazonium salts: A bucky paper electrode. J Am Chem Soc 2001, 123: 6536-6542.

[13] O’Connell MJ, Boul P, Ericson LM, et al. Reversible water-solubilization of single-walled carbon nanotubes by polymer wrapping. Chem Phys Lett 2001, 342: 265-271.

[14] Kónya Z, Vesselenyi I, Niesz K, et al. Large scale production of short functionalized carbon nanotubes. Chem Phys Lett 2002, 360: 429-435.

[15] Holländer A, Thome J, Keusgen M, et al. Polymer surface chemistry for biologically active materials. Appl Surf Sci 2004, 235: 145-150.

[16] He P, Wang SD, Wong WK, et al. Vibrational analysis of oxygen-plasma treated indium tin oxide. Chem Phys Lett 2003, 370: 795-798.

[17] He W, Guo Z, Pu Y, et al. Polymer coating on the surface of zirconia nanoparticles by inductively coupled plasma polymerization. Appl Phys Lett 2004, 85: 896-898.

[18] Flashaut E, Peigney A, Laurent Ch, et al. Carbon nanotube-metal-oxide nanocomposites: Microstructure, electrical conductivity and mechanical proporities. Acta Mater 2000, 48: 3803-3812.

[19] Bhaumik SK, Upadhyaya GS, Vaidya ML. Full density processing of complex WC-based cemented carbides. $J$ Mater Process Tech 1996, 58: 45-52.

[20] Shetty DK, Wright IG, Mincer PN, et al. Indentation fracture of WC-Co cermets. J Mater Sci 1985, 20: $1873-1882$.

[21] Xu T, Yang J, Liu J, et al. Surface modification of multi-walled carbon nanotubes by $\mathrm{O}_{2}$ plasma. Appl Surf Sci 2007, 253: 8945-8951.

[22] Zhang F, Shen J, Sun J. Processing and properties of carbon nanotubes nano-WC-Co composites. Mat Sci Eng A 2004, 381: 86-91.

[23] Zheng Y, Liu W, Wang S, et al. Effect of carbon content on the microstructure and mechanical properties of Ti(C,N)-based cermets. Ceram Int 2004, 30: 2111-2115.

Open Access The articles published in this journal are distributed under the terms of the Creative Commons Attribution 4.0 International License (http://creativecommons.org/licenses/ by/4.0/), which permits unrestricted use, distribution, and reproduction in any medium, provided you give appropriate credit to the original author(s) and the source, provide a link to the Creative Commons license, and indicate if changes were made. 